\title{
OPTIMIZATION OF THE HEAT TREATMENT PROCESS OF A STEEL POROUS CHARGE USING AN INTEGRATED MODELLING
}

\author{
Rafał Wyczółkowski', Agnieszka Benduch ${ }^{1}$ \\ 1 Department of Industrial Furnaces and Environmental Protection, Częstochowa University of Technology, Al. \\ Armii Krajowej 19, 42-200 Częstochowa, Poland, e-mail: abenduch@wip.pcz.pl
}

Received: 2014.08 .30

Accepted: 2014.10 .25

Published: 2014.12.01

\begin{abstract}
The paper discusses the structure and principle of operation of programs for integrated modelling of the processes of heat treatment of porous-structure steel charges, such as long product bundles or strip or wire coils. Consideration is given to the specificity of these models in respect to porous charges. This is associated with their untypical thermal properties, which are expressed using the concept of effective thermal conductivity.
\end{abstract}

Keywords: porous charge, heat treatment, integrated modelling, effective thermal

conductivity.

\section{INTRODUCTION}

Technological operations involving the heat treatment of steel products may significantly influence the efficiency and energy intensity of production, the emission of pollutants and the quality of finished products $[1,2]$. Therefore, efforts are being made to achieve the capability to control the technological parameters of the process of a particular heat treatment operation in a precise and, at the same time, continuous manner. The main difficulty in such control is the lack of opportunity to directly monitor changes in the microstructure of material being treated. Those changes are determined indirectly, based on the data from temperature measurements taken at selected points in the furnace. This approach is quite inconvenient, because thus measured temperature may considerably deviate from the actual temperature of the charge being either heated or cooled.

An extremely attractive alternative in this respect is mathematical modelling. Computer simulation of heat treatment processes using numerical methods is a relatively cheap and effective means of their optimization. The development of information technology and, above all, the increase in computing power, offers a great potential to these methods [3]. In the simplest case, a mathematical model of a process can apply to thermal problems, being limited to computing only the temperature field in an element being treated. Models of this type have been very successfully used in the metallurgical processes for over three decades $[4,5]$. The most developed in this respect are integrated models, which, in addition to the temperature, determine also the microstructure and mechanical properties of an element being heated $[6,7,8]$. Computation results yielded by these models provide primarily the knowledge of the current mechanical properties of the treated elements. Owing to this, it is possible to effectively control the technological process by determining the optimal values of its parameters by computational means [9].

\section{THE SPECIFICITY OF HEATING A POROUS CHARGE}

In numerous cases of heat treatment of steel elements, the charge introduced to the furnace is characterized by a porous structure. It can be divided into two basic categories: coils and bundles 
[10]. In the form of coils, sheet, strip, wire rod and wire are heated. Whereas, different types of long elements, such as bars or tubes, are heated in bundles. Porous charges are distinguished by the existence of a steel solid phase skeleton, within which voids (pores) filled with gas occur. In coils, this skeleton is made up of wire or strip turns, while in bundles, individual long products. Another important feature of these elements is lack of the continuity of the solid phase in specific directions. For this reason, the charges under discussion can be regarded as porous media with a grainy structure.

Due to the structure of porous charges described above, a complex heat transfer occurs within them during heating. For example, the following can be distinguished in a bundle of bars: conduction in the bar cross-section, conduction in the gaseous phase region, contact conduction in the bar contact location, and radiation between bar surfaces. For this reason, the ability of porous charges to transfer heat is an effective quantity and it is therefore termed the effective thermal conductivity [11].

It should be emphasized that, in contrast to the thermal conductivity $l$ of solid materials, the effective conductivity is not a material's property. Due to the lack of the continuity of porous charge's solid phase and the presence of pores filled with gas, the values of the coefficient $l_{\text {ef }}$ of those elements are much lower than the thermal conductivity of the steel alone. This is highlighted by the diagrams in Figure 1, representing the effective thermal conductivity measurement results obtained for flat beds made up of round bars of low-carbon steel with a carbon content of $0.2 \%$ C. From the point of view of charge structure, these beds correspond to bundles of bars. The data in these diagrams are expressed in the form of the reduced $K_{\text {ef }}$ as the quotient of the effective thermal conductivity $l_{\text {ef }}$ of samples by the thermal conductivity $l$ of their metallic phase. As can be seen, the effective conductivity of these beds is smaller by approximately an order of magnitudes than the thermal conductivity of steel. What is characteristic is that it increases with the increase in the lateral dimension of the bars. The observed relationships indicate also that, in contrast to the conductivity of steel, the $l_{\text {ef }}$ coefficient increases as a function of temperature. This can be explained by the intensity of thermal radiation in charge pores increasing with temperature and by the increase in the thermal conductivity of the gaseous phase.

Therefore, relatively small values of thermal conductivity cause considerable temperature differences to occur in the cross-section of those bundles during heating. This is an unfavourable phenomenon, as it contributes to a considerable spatial diversification of the microstructure, and thus also the mechanical properties. To eliminate this undesirable effect, soaking operations are used. The correct definition of the duration of those operations for a given type of porous charge is a complex and difficult problem. Very helpful to this end is integrated modelling, whereby the heat treatment parameters, including also the soaking duration, are determined based on the required final mechanical properties of the material to be treated.
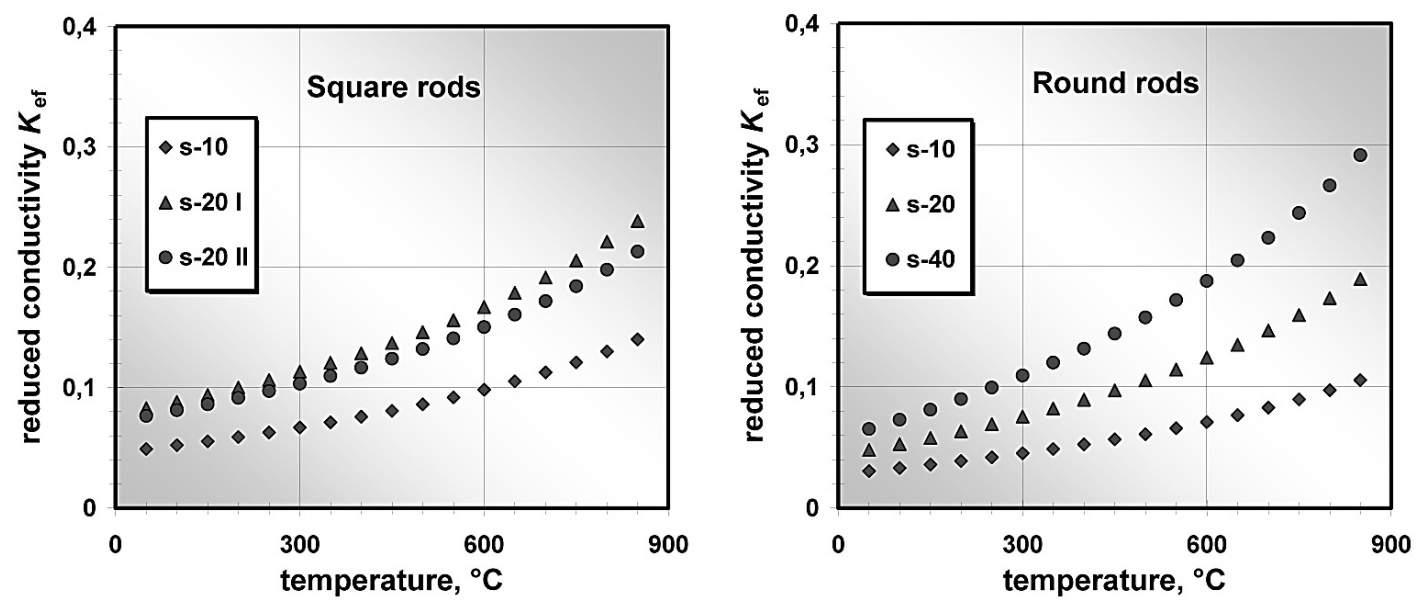

Fig. 1. The results of measurements of the effective thermal conductivity of beds of round and square bars in a reduced form - the numerical value in the sample symbol denotes the lateral dimension of bars in $\mathrm{mm}$ 


\section{THE GENERAL STRUCTURE OF INTEGRATED MODELS}

The numerical algorithms of integrated models rely on the equations of heat transfer, the kinetics of recrystallization and grain growth, and on the correlations between the microstructure of a given material and its mechanical properties $[6-8,12]$. In these models, based on input data such as material grade, charge dimensions, furnace geometry and operation parameters, and planned heat treatment cycles, the time and spatial distribution of temperature within the charge is determined in the first place. Then, based on the information on the formation of the temperature field, the grain size distribution and mechanical properties of the material are estimated.

In view of the described procedure, three separate modules can be distinguished within integrated models: the thermal, the microstructural transformation, and the mechanical properties modules. In the thermal module, calculations of the time and spatial temperature changes within the charge are made. The results of these calculations are then used as input data for the microstructural transformation module, in which the sizes of grains formed during heating of metal are determined. The knowledge of the microstructure of the material enables its mechanical properties to be determined in the last module.

\section{THE CONFIGURATION AND PRINCIPLE OF OPERATION OF THE THERMAL MODULE}

The design of the thermal module must allow for thermal interactions occurring between the charge and various elements of the furnace, which are associated with the complex mechanisms of conduction, convection and radiation. Information on changes in the temperature field within the charge is obtained by solving the Fourier-Kirchhoff (F-K) heat equation [13]. The form of this equation depends on the geometry of charge being heated. As the porous charge has most commonly a cylindrical shape (coils being regarded as rings, while bundles as solid cylinders), thermal modules use the F-K equation as written for the cylindrical coordinate system.

Obtaining the analytical solution of the F-K equation is only possible for identical uniqueness conditions [13]. For processes showing variability of these conditions, the solution can only be achieved using numerical methods. One of the methods used for the calculation of the temperature field of heated charge in computerized implementations is the finite difference method [14]. In this method, the starting differential heat equation is expressed in the form of finite differences, which involves the division of the region under analysis into elementary parts using a difference division grid $[3,13,15]$. Substituting the forward difference quotient for the time derivative yields a system of equations in which only one unknown occurs, which is temperature in a given difference grid node $i$ for the successive time step $k+1$, denoted by the symbol $T_{\mathrm{i}, \mathrm{k}+1}$. The obtained system of equations needs to be complemented with boundary and initial conditions. Their form depends on the technological conditions being associated, e.g., with the type and design of the furnace used.

In modelling of porous charge heating, it is crucial to determine the value of the $l_{\text {ef }}$ coefficient, as one of the uniqueness conditions. These issues have not been sufficiently extensively covered so far in the literature on the subject [16]. The most appropriate solution of this problem is to incorporate a suitable numerical procedure for determining the current value of the $l_{\text {ef }}$ coefficient in the thermal model. These computations are performed by analyzing the thermal resistance $R_{\mathrm{t}}$ of an elementary cell isolated from the charge concerned. This approach takes advantage of the analogy between the electric current flow and the heat transfer phenomena. The effective conductivity searched for is calculated as the quotient of the resistance $R_{\mathrm{t}}$ to the characteristic dimension of the cell in the heat transfer direction. This problem is discussed in a greater detail in study [17] on the example of several types of porous charge.

\section{THE MICROSTRUCTURAL TRANSFOR- MATION AND MECHANICAL PROPERTY MODULES}

This module uses primarily the Avrami equation that describes the variations in the fraction of recrystallized grains $X$ as a function of time [12]:

$$
X=1-\exp \left(-K_{r e} \tau^{n_{r e}}\right)
$$

where: $K_{\mathrm{re}}-$ a temperature-dependent constant, $n_{\mathrm{re}}-$ the Avrami exponent. 
The values of these parameters for a specific steel grade are determined based on experimental tests that involve the determination of the value of the $X$ parameter in isothermally soaked samples for different time intervals, ranging from several to several hundred minutes.

After transforming Equation (1) into the form of $\ln [\ln (1 /(1-X))]=\ln K_{r e}+n_{r e} \ln t$, the values of the exponent $n_{\text {re }}$ and the constant $K_{\text {re }}$ are determined based on the analysis of the graph, in which the experimental data are approximated with a linear relationship (Figure 2a) [12]. The values of the parameter $\ln K_{\mathrm{re}}$ are the absolute terms, whereas the exponent $n_{r e}$ corresponds to the slopes of the lines.

Thus determined $K_{\mathrm{re}}$ constants are a function of the crystal nucleation and growth rate, as described by the relationship $[12,19]$ :

$$
K_{r e}^{\frac{1}{n_{r e}}}=k_{0} \exp \left(-\frac{Q_{r e}}{R T}\right)
$$

where: $Q_{\text {re }}$ - the activation energy characteristic of the process of transformations of the crystalline structure in question.

The values of this parameter are determined based on the analysis of the experimental data summarized in the form of the diagram shown in Figure $2 b$ [12].

In the same way, the parameters describing the grain growth kinetics are determined. To this end, grain size measurements should be taken on samples isothermally soaked at different temperatures. The mean grain growth rate is described by the relationship [12]:
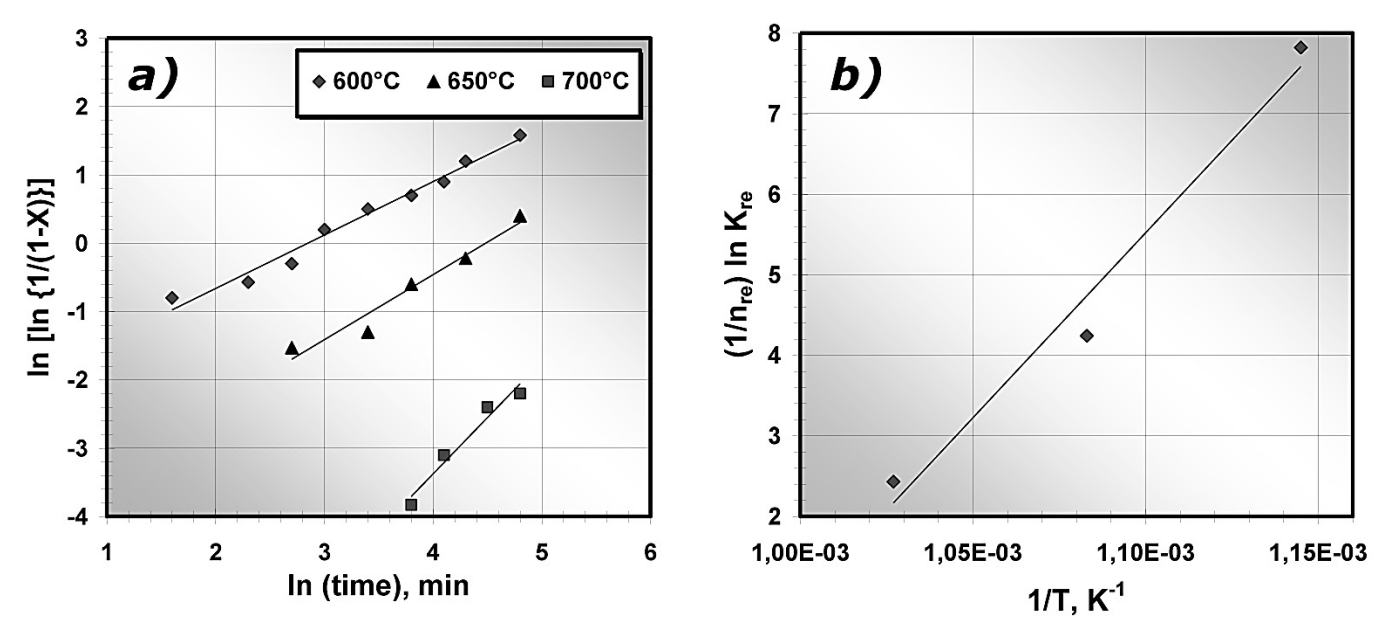

Fig. 2. a) the graph of the parameter $X$ as a function of the logarithm of time, b) the graph for the determination of the activation energy for the recrystallization process [12]
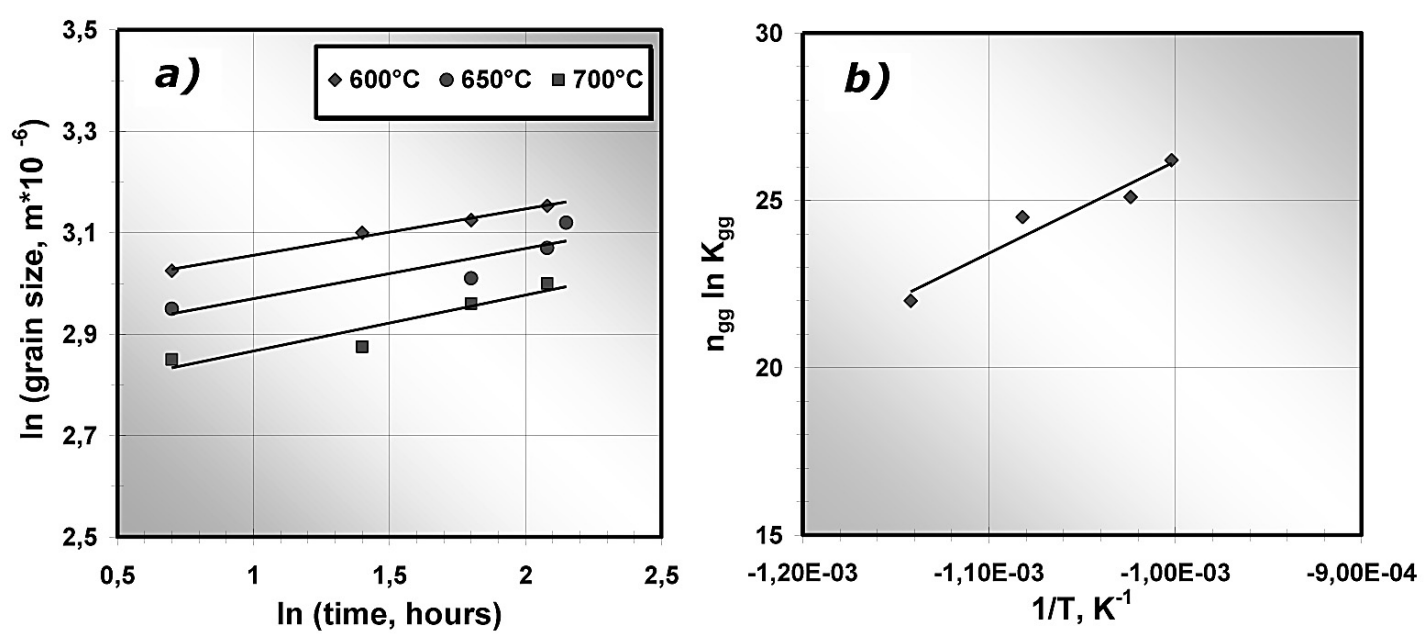

Fig. 3. a) the graph of the grain size $d_{\mathrm{gg}}$ as a function of the logarithm of time, b) the graph for the determination of the activation energy for the grain growth process [12] 


$$
d_{g g}=K_{g g} \tau^{\frac{1}{n_{g g}}}
$$

where: $d_{g g}-$ the mean metal grain size after the time $t$.

The values of the coefficient $K_{\mathrm{gg}}$ and the exponent $n_{\mathrm{gg}}$ are determined from the logarithmic graphs representing the relationship of grain size as a function of annealing duration (Figure 3a). The value of the constant $K_{\mathrm{gg}}$ is described by the relationship [12]:

$$
K_{g g}^{n_{g g}}=k_{0} \exp \left(-Q_{g g} /(R T)\right)
$$

The value of grain growth activation energy $Q_{\mathrm{gg}}$, occurring in Equation (4), as illustrated in Figure $3 b$, is obtained from the analysis of the graph representing the relationship of $n_{\mathrm{gg}} \ln K_{\mathrm{gg}}$ as a function of the inverse of absolute temperature [12].

After determining the grain size value, further computations are performed in the mechanical property module. First of all, the yield strength of the material is determined. For the determination of this parameter, the Hall-Petch relationship is used, which describes the effect of the mean grain size $d_{\mathrm{gg}}$ on the value of the lower yield stress $\sigma_{\mathrm{d}}[18]$ :

$$
\sigma_{d}=\sigma_{0}+k \cdot d_{g g}^{-0,5}
$$

where: $\sigma_{0}, k$ are constants, whose values for a specific steel grade are determined based on experimental tests.

Similar procedures are used for determining the tensile strength.

\section{CONCLUSIONS}

Integrated heat treatment process models, operating according to the description given above, are successfully used on industrial lines for various types of porous charge. They are most often employed for controlling the annealing of sheet coils in bell-type furnaces $[6,19]$ and bundles of bars in continuous furnaces $[7,8]$. In view of their thermal properties, these elements require soaking. Integrated models make it possible to establish the optimal duration of this operation. Thanks to this, these tools contribute to the reduction of production costs by reducing energy consumption, increasing productivity, minimizing the costly industrial tests and improving the quality of manufactured products [19].
It should be emphasized that prior to implementing it for the control and monitoring of a specific industrial process, an integrated program requires careful validation of each of its component modules. The validation procedures are carried out based on the data obtained both from industrial trials and from laboratory tests $[12,19]$. This issue, though very important from the point of view of the correctness of operation, has not been discussed in this paper for the reasons of its space.

\section{REFERENCES}

1. Mehta R., Sahay S.S.: Heat transfer mechanism and furnace productivity during coil annealing: aluminium vs. steel. Journal of Materials Engineering and Performance, Vol. 18(1), 2009, 8-15.

2. Rudnik S.: Physical metallurgy. PWN, Warszawa 1996 (in Polish).

3. Adrian H.: Numerical modeling heat treatment process. Wydawnictwa AGH, Kraków 2011 (in Polish).

4. Jaluria Y.: Numerical simulation of the transport process in a heat treatment furnace. International Journal for Numerical Methods in Engineering, 25, 1988, 387-399.

5. Rao T.R., Barth G.J., Miller J.R.: Computer model prediction of heating, soaking and cooking times in batch coil annealing. Iron and Steel Engineering, 60 (9), 1983, 22-33.

6. Sahay S.S., Kumar A.M.: Application of integrated batch annealing furnace simulator. Materials and Manufacturing Processes, Vol. 17 (4), 2002, 439-453.

7. Sahay S.S., Krishnan K.: Model based optimization of continuous annealing operation for bundle of packed rods. Ironmaking and Steelmaking, Vol. 34 (1), 2007, 89-94.

8. Sahay S., Mehta R., Krishnan K.: Genetic-algorithm-based optimization of an industrial age-hardening operation for packed bundles of aluminum rods. Materials and Manufacturing Processes, 22, 2007, 615-622.

9. Wyczółkowski R.: Integrated modeling heat treatment process of porous charge. In: A. Kawałek (ed.). Metallurgy, New technologies and achievements. Series: Monographs No 25, Częstochowa 2012, 40-50 (in Polish).

10. Wyczółkowski R.: Classification and characterization of porous charge found in the industrial heat treatment practice. Hutnik-Wiadomości Hutnicze, Vol. 12, 2012, 877-879 (in Polish).

11. Wyczółkowski R., Benduch A.: Effective thermal conductivity as primary thermal parameter 
of porous charge. In: XII Międzynarodowa Konferencja Naukowa „Nowe technologie w metalurgii i inżynierii materiałowej. Monografie nr 15, Częstochowa 2011 (in Polish).

12. Sahay S., Kumar M., Chatterjee A.: Development of integrated model for batch annealing of cold rolled steels. Ironmaking and Steelmaking, 2004, Vol. 31 (2), 144-152.

13. Wiśniewski S., Wiśniewski S.T.: Heat transfer. WNT, Warszawa 2012 (in Polish).

14. Piechowicz Ł., Wyczółkowski R., Łukaszek D.: Mathematical model of thermal process on the basis of installation to annealing coils of aluminum sheet. Report from investigatory project order by SECO/WARWICK ThermAL S.A., Świebodzin 2012.
15. Gdula S.J. (ed.): Heat conduction. PWN, Warszawa 1984 (in Polish).

16. Wyczółkowski R.: Selected problems connected with hating up of steel charge of porous structure. In: Metalurgia. Nowe technologie i osiągnięcia, Częstochowa 2009, 337-359 (in Polish).

17. Wyczółkowski R.: Modeling of the thermal properties of porous charge by application of the elementary cell concept. In: Wybrane zagadnienia produkcji i zarządzania w przedsiębiorstwie. Seria: Monografie nr 29, Częstochowa 2012, 54-65.

18. Przybyłowicz K.: Physical metallurgy. PWN, Warszawa 2007 (in Polish).

19. Sahay S.S., Kumar A.M.: Applications of integrated batch annealing furnace simulator. Materials and Manufacturing Processes, Vol. 17(4), 2002, 439-453. 